ojs.uv.es/index.php/qfilologia/index

Rebut: 02.05.202I. Acceptat: 28.10.202I

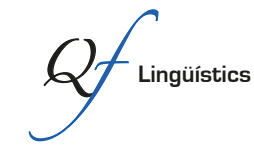

Per a citar aquest article: Carrizo, Alicia E. 202I. "Estudio de la violencia en el discurso mediático durante la pandemia: el caso de Abigail Jiménez”. Quaderns de Filologia: Estudis Lingüístics XXVI: 247-266.

doi: $10.7203 /$ QF.26.21986

\title{
Estudio de la violencia en el discurso mediático durante la pandemia: el caso de Abigail Jiménez
}

Study of violence in discourse during the pandemic: the case of Abigail Jiménez

Alicia E. Carrizo

Universidad de Buenos Aires

aliciaecarrizo@gmail.com

Resumen: El propósito del trabajo es dar cuenta de una situación de abuso de autoridad que se desarrolla en un retén policial cuando le impiden el paso a una niña enferma de cáncer, en el marco de la pandemia de la COVID-I9. Analizaremos la situación como un caso de violencia no manifiesta y su posterior representación en el discurso mediático. El corpus está constituido por notas de medios digitales locales que incluyen el video del intercambio entre el policía y el padre y entrevistas a la familia. Se utilizará como marco teórico el análisis lingüístico del discurso y de la argumentación interaccional con perspectiva crítica y etnográfica.

Palabras clave: violencia; conflicto; pandemia; análisis del discurso.

Abstract: The purpose of the paper is to account for a situation of abuse of authority that develops in a police checkpoint when a girl with cancer is prevented from passing, in the context of the COVID-I9 pandemic. We will analyze the situation as a case of non-manifest violence and its subsequent representation in the media discourse. The corpus is made up of local digital media notes that include the video of the exchange between the policeman and the father and family interviews. The linguistic analysis of discourse and interactional argumentation with a critical and ethnographic perspective will be used as a theoretical framework.

Keywords: violence; conflict; pandemic; discourse analysis.

\section{Introducción}

Milagros Abigail Jiménez era una paciente oncológica de I2 años que recibía cuidados paliativos en el Hospital Jesús Niño de San Miguel de Tucumán por un cáncer en la rodilla -sarcoma de Ewing- que padecía desde los 7 años. El i6 de noviembre de 2020 , cuando volvía a su hogar con sus padres en Termas de Río Hondo, provincia de Santiago del Estero, un policía de la caminera les 
impidió el ingreso porque el vehículo en el que se trasladaban no cumplía con el protocolo provincial adoptado por la pandemia de la COVID-Ig. Ante la demora en la resolución del problema, el padre decidió cruzar el límite provincial a pie con su hija en brazos. Al día siguiente, se viraliza una ilustración del padre con Abigail en brazos que moviliza a la opinión pública. Dos meses después, la niña fallece en su casa natal.

Analizaré la situación como un caso de violencia no manifiesta y su posterior representación en el discurso mediático. El corpus seleccionado para este trabajo se recolectó de las notas a medios locales publicadas al día siguiente del hecho e incluye el video del intercambio entre el policía y el padre y entrevistas de los medios a la familia. El punto de partida es que la violencia no manifiesta, al igual que la estructural (Garver y Friderber, I968; Farmer, 2004) se explica, solo en parte, por efecto de las carencias en el funcionamiento del Estado (Pardo y Carrizo, 20I8). El análisis del discurso integrará la lingüística sistémica funcional como teoría base, con aportes del análisis interaccional y la argumentación desde una perspectiva crítica y etnográfica (Carrizo, 20I9; Halliday, I985; Menéndez, 2019; Pardo, 2008; van Dijk 2016). Los resultados preliminares del análisis del conflicto en la caminera dan cuenta de la violencia encubierta por parte del agente policial. Para la familia Jiménez, salir de esa situación implicó un acto de asertividad contraargumentativo para redefinir su posicionamiento social. En este sentido, la reconstrucción de la situación por parte de la familia durante las entrevistas en los medios contribuyó a la configuración de una narrativa que fue estratégica para negociar su situación sociosanitaria.

\section{Entorno normativo en Argentina}

El II de marzo de 2020, la Organización Mundial de la Salud (OMS) declaró pandemia el brote del nuevo coronavirus SARS-Cov2 Corona Virus Disease 2019 (COVID-I9). En Argentina, se estableció el aislamiento social, preventivo y obligatorio (ASPO) para todas la personas que residen en el país, en los términos indicados en el Decreto 297/2020 y se implementaron un conjunto de iniciativas sociales, económicas y fiscales dirigidas a paliar la vulneración de derechos desencadenados por el aislamientor.

\footnotetext{
${ }^{\text {I }}$ Para un listado completo de las normas publicadas en el Boletín Oficial de la República Argentina en relación con la emergencia sanitaria por coronavirus COVID-I9, véase el digesto que actualiza diariamente el Ministerio de Justicia y Derechos Humanos de la Nación en https://www.
} 
El ASPO configuró un contexto restrictivo para el desarrollo habitual de las relaciones sociales. En este sentido, la Secretaría de Derechos Humanos de la Nación impulsó diversas acciones de protección y recomendaciones para garantizarlos durante la pandemia de la COVID-I9. Las recomendaciones de la Secretaría tuvieron en cuenta, especialmente, que los funcionarios y/o agentes públicos pueden interferir y alterar la autonomía y la libertad de las personas, lo que constituye, entonces, una restricción de derechos.

La relación de la sociedad con la COVID-ig también fue cambiando en sintonía con la extensión en el tiempo del aislamiento y la constante propagación del virus. Al poco tiempo, quedó en evidencia que la crisis sanitaria no era homogénea dentro del territorio nacional y se adoptaron modalidades de cuarentena diferenciadas, según la realidad de las distintas jurisdicciones provinciales (DNU 355/2020). Entre las medidas aprobadas se estableció un permiso de circulación especial entre jurisdicciones (Resolución 132/2020, MDS (B.O. 2I/03/2020) para proteger la salud física, psíquica y emocional de niños, niñas y adolescentes.

Sin embargo, la Asamblea Permanente por los Derechos Humanos (APDH) publicó el 26 de marzo de 202I un dosier de denuncias, declaraciones e informes que da cuenta del incremento de la violencia institucional en el país desde que comenzó el aislamiento por la pandemia de COVID-I9, entendiendo que estas situaciones fueron ejercidas, principal pero no exclusivamente, por las Fuerzas de Seguridad.

\section{La violencia en el análisis del discurso}

El análisis del discurso enfoca el estudio de la violencia en términos de conflicto interpersonal, descortesía y violencia verbal (Labov, I972; Kerbrat Orecchioni, I980; Grimshaw, I990; Haverkate, I988; Rosier, 2007, 2012; Fracchiolla et al., 20I3; Moïse \& Oprea, 20I5; Vincent \& Barbeau, 20I2; Amossy, 20I7). En este sentido, el enfoque interaccionista de los estudios sociales recobró el papel del conflicto en las relaciones interpersonales. Erving Goffman (200I) propone una perspectiva dramatúrgica para estudiar las entidades y las interacciones sociales según la cual los actores sociales luchan por sostener los elementos que definen una situación social tal como ha sido proyectada

argentina.gob.ar/noticias/digesto-de-emergencia-sanitaria-por-coronavirus. Véase también el detalle de las medidas adoptadas por el Gobierno nacional en https://www.argentina.gob.ar/ coronavirus /medidas-gobierno. 
frente a otros. Goffman caracteriza la violencia como una acción social disruptiva y argumenta que aún la forma más desnuda de coerción física no es ni objetiva ni desnuda, sino que funciona como un despliegue para persuadir a la audiencia, un medio de comunicación y no simplemente un medio de acción (Goffman, 200I: 24I).

Asociándolas en un principio a un "desorden" del discurso, las investigaciones iniciales sobre conflicto en el ámbito de los estudios lingüísticos enfocaron las propiedades estructurales de las disputas, como por ejemplo el trabajo de Labov (I972) sobre las peleas ritualizadas de adolescentes de Harlem (Nueva York). Al mismo tiempo, la argumentación, en virtud de su organización discursiva interna, reduce la tensión de la disputa al regular el contexto de conflicto (Carrizo, 20I2) y, fundamentalmente, al dar una salida a los participantes que les permite (re)negociar los términos y continuar con la interacción en curso.

Moïse (2OI2) reconoce tres tipos de violencia verbal, la rápida o fulgurante (detonada por cambios abruptos del contexto); la polémica (retórica) y la indirecta o con rodeos (no manifiesta) que se desarrolla en situaciones ambiguas, manipuladas por una relación de poder, por ejemplo, en intercambios con un guarda de tren, un agente en el control de alcoholemia o el personal de vigilancia. Más adelante veremos que la situación que se plantea en el retén policial constituye una situación de violencia no manifiesta, en la que el daño incluye un intercambio conversacional a raíz de la contravención, una relación interpersonal controlada por el poder de una de las partes, un entorno medioambiental agobiante y la enfermedad de la niña en etapa terminal ${ }^{2}$.

Recuperamos además el trabajo de Farmer (2004), quien propone una etnografía de la violencia estructural, lo cual nos exige ampliar el concepto y conceptualizar la violencia como un continuo de fenómenos sociales que van del asalto físico directo a la violencia simbólica y a la violencia cotidiana rutinaria, incluida la violencia estructural crónica. Sin un marco disciplinar propio, la violencia es un concepto resbaladizo que incluye ataques contra el respeto propio y la personalidad. Las dimensiones sociales y culturales son las que le dan su fuerza y significado, nos recuerdan también que la mayoría de los actos violentos no son desviados ni casuales. Se definen como morales al

\footnotetext{
${ }^{2}$ Los cuidados paliativos tienen reconocimiento como derechos humanos y han recibido reconocimiento legal en Argentina a través de normativas de diferente rango (Resolución $\mathrm{N}^{\circ}$ 643/00 y Resoluciones N587/I0 y N² I253/E/I6 MSN).
} 
servicio de las normas convencionales y los intereses materiales (Scheper-Hughes \& Bourgois, 2004).

En consonancia con el enfoque integral y amplio de la violencia, la perspectiva crítica del análisis del discurso entiende los discursos en torno a la violencia como prácticas sociales que dan cuenta de las relaciones de dominación, discriminación, poder y control tal como se manifiestan en los usos del lenguaje en el discurso.

\section{Análisis del caso de Abigail}

\subsection{Marco teórico metodológico}

Argumentar implica que se ha renunciado a recurrir únicamente a la fuerza para defender una posición. Cuando una de las partes discute, se argumenta y se asume una posición que se defiende de distintas maneras. Una de ellas es mediante estrategias discursivas de argumentativas destinadas sobre todo a redefinir las relaciones interpersonales entre los participantes. Constituye una práctica discursiva que se usa en los casos de disputa como una especie de "sintaxis del conflicto", un mecanismo de comportamiento social que pauta el enfrentamiento. Al igual que en otros casos de riesgo y amenaza de la imagen social (Brown \& Levinson, I987), la tensión entre los participantes y, sobre todo, la relación de poder repercuten en la organización de la conversación.

Analizamos tres dimensiones de la argumentación: la estructura lógica, la disputa dialéctica y la retórica persuasiva (Carrizo, 2012, 2019). La dimensión lógica se refiere a la organización de los argumentos; reconocemos como recursos las acciones lógicas, la estructura argumental del silogismo y los esquemas (van Eemeren \& Garssen, 2020). La dimensión dialéctica tiene que ver la gestión del enfrentamiento; los recursos que señalamos son la posición dialéctica, los roles de los participantes y el desarrollo del conflicto, según las

\footnotetext{
3 El contexto de conflicto (Carrizo, 20I2) integra recursos conceptuales que surgen de la secuencia escalar de la disputa, la secuencia conversacional, la amenaza de la imagen y las estrategias argumentativas de los participantes. Alude a los elementos cognitivos y objetivos de la situación donde se desarrolla el intercambio que permiten entender lo que se dice y comunica. Considerando el contexto como resultado de la actividad reflexiva y conjunta de los participantes, el conflicto emerge bajo la forma de interpretaciones dispares entre sí y comprende una serie encadenada de actos comunicativos, en la que los participantes controlan y basan sus acciones en las acciones del otro (Levinson, I989: 38 ).
} 
etapas de discusión (van Eemeren, Grootendorst \& Henkemann, 2006). Y, por último, la dimensión retórica enfoca la persuasión que se logra a través de la comunicación; los recursos enfocan los comportamientos de los participantes, los marcos invocados y los movimientos de participación y posición que surgen de los cambios en el alineamiento. Desde una perspectiva social (Du Bois, 2007), el posicionamiento es el acto público de un actor social, logrado dialógicamente a través de medios comunicativos encubiertos que simultáneamente evalúa objetos, posiciona sujetos (a sí mismo y otros), y alinea al sujeto con otros respecto a alguna dimensión del campo sociocultural.

Para llevar a cabo el análisis del corpus, la lingüística sistémica funcional como una semiótica discursiva y social (Halliday, I985; Martin \& White, 2005; van Leeuwen, 2008; Pounds, 20I2; Bednarek \& Caple, 20I7) operará como acercamiento inicial a los datos, a partir de la cual se interpretarán las dimensiones lógica, dialéctica y retórica de la argumentación (Carrizo, 20I2) integrando al análisis movimientos interaccionales de participación y posicionamiento (Goffman, I974, I98I; Gumperz, I982; Du Bois, 2007; Carrizo, 2019) desde la perspectiva del análisis estratégico del discurso (Menéndez 2009, 2019) y el análisis crítico del discurso (van Dijk, 20I6; Pardo, 2008; van Leeuwen, 2008).

La hipótesis inicial es que la recontextualización coparticipada de la situación del retén en las sucesivas entrevistas de la familia va construyendo la narrativa familiar del caso como abuso policial en el discurso mediático. La pregunta inicial es qué estrategias discursivas se ponen en juego para construir un relato adecuado de la agresión sufrida.

\subsection{Corpus}

El corpus completo de la investigación está constituido por siete notas emitidas entre el I7 y el 2I de noviembre de 2020 en medios locales y nacionales digitales ${ }^{4}$. Para este artículo, seleccionamos dos instancias ocurridas el I7 de noviembre de 2020 :

- La situación del retén videograbado que se difunde en el semanario El Termeño (https://fb.watch/5ykipfqo_U/).

\footnotetext{
${ }^{4}$ El trabajo se realiza como parte de los estudios posdoctorales sobre "La construcción del discurso violento en contextos públicos” dirigida por la Dra. María Laura Pardo (FFyL. UBA Resolución I557 (CD) 20I5) en el marco de la investigación Conicet "Violencia y derechos vulnerados: el discurso en acción”. Proyectos de Investigación Plurianuales (PIP II220I70100050C).
} 
- Entrevista a la familia Jiménez difundida en Facebook trasmitida en vivo en El Termeño (https://fb.watch/5ygOCa8Wqx/).

En el primer caso, se hará foco en la negociación del conflicto y en el otro, en la narrativa de experiencia personal contextualizada en la entrevista; se analizará el comportamiento argumentativo y la evaluación narrativa (Labov, 20I3). Desde el punto de vista metodológico, el análisis del discurso interaccional (Carrizo, 20I2) prefiere el registro de datos en situaciones reales y espontáneas de habla en combinación con técnicas etnográficas. Si bien la recolección no sigue las pautas del trabajo de campo, la grabación familiar supone un registro como participante involucrado, al igual que la entrevista en el medio local (Duranti, 2003). Sin duda esta decisión acarrea problemas teóricos y metodológicos, sobre todo al tomar la entrevista periodística5. La decisión de trabajar con este tipo de material se debe a que nos permite contar con una amplia muestra de situaciones de lenguaje en uso enmarcadas contextualmente $^{6}$.

Por otra parte, entendemos que la distinción entre la negociación y la entrevista recurre a la noción de género definida como un patrón configurativo del campo, el tenor y el modo que se sitúa en la cima de la escala de la realización, en el nivel más alto de abstracción (Martín \& White, 2005).

El video del retén se difunde en los medios nacionales, luego aparece una ilustración en twitter que retoma la foto del padre y el caso se viraliza en redes sociales y medios de comunicación. Con la divulgación nacional del caso, interviene el poder político nacional.

\footnotetext{
${ }^{5}$ El análisis del discurso de la argumentación interaccional enfoca las categorías que estructuran el discurso y su manipulación estratégica (Condor y Antaki, 2000) con el fin de acceder a las representaciones discursivas y al conjunto de prácticas discursivas y extradiscursivas de las que disponen los sujetos. Los sujetos adaptan los discursos y las prácticas disponibles en función de la situación comunicativa (Verschueren, 2002). Para el analista, la reconstrucción de los dispositivos estratégicos explica el funcionamiento discursivo de los sujetos en relación con el objetivo interaccional que persiguen (Menéndez, 2009).

${ }^{6}$ Adoptamos la distinción propuesta por Halliday y Matthiessen (2004:3) respecto de la posibilidad de enfocar el estudio de los textos, ya sea como artefactos o como espécimen. En cuanto que artefacto, el estudio del texto se centra en las características propias inherentes que lo definen como tal; en cambio, una instancia de lenguaje en cuanto que espécimen, sirve como instrumento para estudiar qué es lo que revela acerca del sistema del lenguaje al que pertenece. Al enfocarlo como espécimen, no hay diferencias entre una interacción extraída de un género ficcional y una interacción videograbada en la vida real (Álvarez-Pereyre, 20II). Ambas cumplen la misma función, son realizaciones concretas de lenguaje.
} 


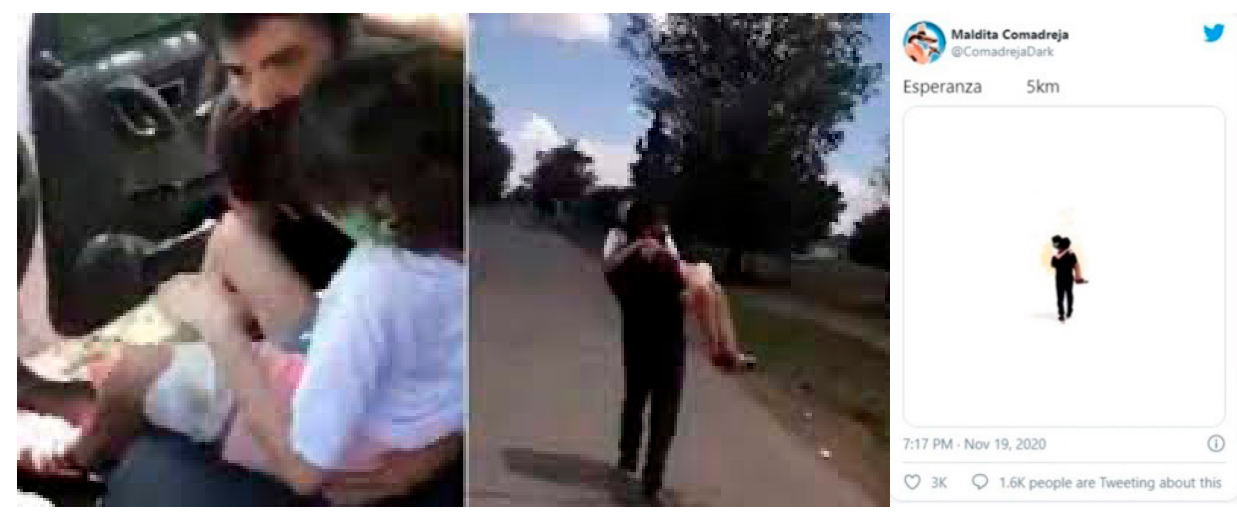

Figura I. Imágenes capturas del video. Ilustración de “@Maldita comadreja

\section{Situación comunicativa en el retén de la policía caminera}

La situación comunicativa se desarrolla el lunes i6 de noviembre de 2020 durante el ASPO en el Puesto Caminero de Yutu Yacu, sobre Ruta Nacional N. ${ }^{\circ}$ 9, en los límites entre Santiago del Estero y Tucumán7. Un policía del retén le prohibe el paso a la familia Jiménez. Abigail tiene la pierna vendada ${ }^{8}$. El padre decide pasar caminando con su hija en brazos aun cuando el policía trata de evitarlo y se interpone. El viaje había sido decidido de urgencia y contaban con el permiso de la municipalidad y la autorización verbal del jefe de Seguridad Ciudadana N. ${ }^{\circ} 6$ de Termas de Río Hondo.

\footnotetext{
7 Meses antes, en el mismo puesto dos policías habían sido acusados de coacción a un comerciante de Termas de Río Hondo para evitar una multa, "la detención del oficial y del suboficial, el resto de los integrantes de la guardia que se beneficiara de la coima, fueron relevados sin funciones y puestos en disponibilidad preventiva". (https://sursantiago.com.ar/policiales/2020/08/28/dos-policias-acusados-de-pedir-coima fueron-detenidos-y-se-preve-su-exoneracion).

${ }^{8}$ Abigail era atendida en el Hospital del Niño Jesús de San Miguel de Tucumán, a $90 \mathrm{~km}$ de Termas de Río Hondo, donde vivía su familia. Había sido trasplantada en el 20i6, se recuperó y en 2019 tuvo una recaída que la llevó a recibir cuidados paliativos.
} 


\subsection{Análisis del intercambio entre el policía y la familia en la ruta}

\section{Transcripción 9}

Primera secuencia. La imagen muestra a Abigail en brazos del padre. Ella llora y se lamenta.

Padre: (yo) la traigo siempre\

(OI) y nunca me hacen problemas.

(a qu-viene?)

en termas me hacen problemas $\backslash$

Qu---[aquí en termas [Aquí en termas

Policía: [no tenemos permiso

Padre: [que no puedo pasar=NO \[no no no]

Policía [(usted tiene que sacar todos los permisos correspondientes) para que no tenga este tipo de problemas

Padre: (o.3) no, no $\backslash$ no es así.

yo me la llevo caminando

Policía: (=ehh, por favor]

Padre: [me la llevo caminando]

Policía: [se- [la va a empeorar señor

Padre: =[Cómo quiere que haga = cómo quiere que me calme $]$

Policía: $=$ [escúcheme Señor]

// el padre se da vuelta para que no lo toque ni le impida el paso

[la va a empeorar señor por favor]

[dejelá]

// el policía estira la mano para que retroceda el padre

(Llora Abigail en brazos del padre, él trata de pasar)

Segunda secuencia. Cambia el lugar, no la situación

Padre: vamos caminando.

Madre: =vamos

//Abre la puerta del auto, el padre se acerca para levantar a la niña en brazos

Padre cómo lo puedo tener aquí,

ieno (lleno) de moscas (O.I),

cómo lo puedo tener,

$=$ [A usted le parece?]

Madre: $=[$ no tenés corazón hermano]

Abigail: mamIII, mamitA, MAmii, papá // llora grita

9 La variedad dialectal del habla en Santiago del Estero (Argentina) presenta características particulares respecto de la variedad rioplatense predominante en el resto del país, que se observa especialmente en la declinación que acompaña al voseo y en el uso del pretérito perfecto compuesto. 
Padre: ya está hija, ya vamos

Policía: (si ustedes se quieren ir / ya son grandes señores / vayansé) yo no me opongo (si quiere llevelá) (Llevelá) //El padre camina por la ruta con Abigail en brazos, llorando

Padre Levantale la (ro)pita Levantale la (ro)pita

Madre Perá

(0.5)

Abigail: Por qué (repite, ahhh por qué

\section{Desarrollo del conflicto}

Brevemente, reconocemos los siguientes movimientos interactivos en el desarrollo del conflicto:

\section{Inicio}

Policía

I. ${ }^{\text {er }}$ movimiento: PROHIBE - Interpone su cuerpo

2. ${ }^{\circ}$ movimiento: JUSTIFICA - informa

Con argumento de causa efecto + finalidad ${ }^{\mathrm{io}}$

Nosotros (exclusivo) no tenemos permiso

Usted tiene que sacar todos los permisos correspondientes

Para que no tenga este tipo de problemas

Deja en posición foco 'problemas'

Refutar: negar la relación causal

Padre

I. ${ }^{\text {er }}$ movimiento: NIEGA

2. ${ }^{\circ}$ movimiento JUSTIFICA - informa

niega con argumentación sintomática

no, no| no es así

\footnotetext{
Io Instrumental: se plantea una relación de causalidad entre el argumento y el punto de vista. Lo que se afirma en la argumentación es un medio, un instrumento o factor causal para el logro de la tesis; incluye las consecuencias de una acción y la reivindicación de la meta por sobre los medios para lograrla (van Eemeren \& Garssen, 2020).
} 
Figura- Rol social padre protector (Goffman, I98I)

Esquema argumentativo sintomático: no es así

Pr: mi hija está enferma

W: entorno situacional es peligroso por calor, bichos

T: en consecuencia: la llevo caminando

zer movimiento: ADVIERTE

Yo me la llevo aunque sea caminando'

En resumen,

POSICIÓN I

El vehículo no pasa sin permiso del Comité de Emergencia de Santiago del Estero (COE)

Actor: el policía

Estructura argumental: instrumental o causal (A causa B).

Para refutar hay que negar la circunstancia o el hecho invocado en A

\section{POSICIÓN II}

Niega no tener permiso

Actor: la familia Jiménez (Daniel, Carmen y Milagros Abigail)

Estructura argumental: analógica (A es comparable a B)

\section{Escalada - Negociación}

Policía: El vehículo no pasa. Ud es el responsable

Estrategia discursiva: indirecta. AHI

la va a empeorar señor, déjela, escúcheme señor, por favor

(intenta refutar por las consecuencias)

Padre: responde al intercambio del policía en los términos planteados por la autoridad policial

Estrategia discursiva: directa, ataca para defender

¿Cómo quiere que haga? ¿Cómo quiere que me calme?

Madre: define la situación como acto (des)humano

No tenés corazón hermano

Estrategia discursiva: argumento ad hominem invoca piedad.

Abigail: percibe la situación como maltrato 
Estrategia discursiva: acto de habla directo sin contenido proposicional que se interpreta argumentativamente (Eisenberg y Garvey, I98I).

Llora, llama a sus padres para pedir contención

\section{Cierre}

Luego de la intervención de la madre, el policía termina redefiniendo su alineamiento, si se quieren ir / ya son grandes señores /vayansé, usa la justificación para mantener la autoridad al dar orden (invoca una condición preparatoria) sin violar la norma. Por otro lado, el padre resuelve pasar con lo que está a su alcance, o sea, con su cuerpo (la lleva a upa). El resultado de la negociación es que ambas partes ganan y protegen su imagen social. El padre logra sacar a su hija del entorno agobiante sin violar el protocolo del COE y el policía mantiene el rol de guardián del orden público.

\section{Interpretación de las estrategias}

En el inicio, observamos que el padre intenta persuadir con ataques directos y abiertos, apelando a un orden moral superior mediante una pregunta retórica de oposición cómo quiere que me calme? /A usted le parece? La madre, en cambio, utiliza una estrategia argumentativa orientada a la dimensión retórica no confrontativa que interpela al policía en su condición humana no tenés corazón hermano. El argumento, entonces, no responde al contenido del asunto en disputa (si pueden o no pasar en auto) sino que invoca un valor común. Da por supuesto que tener corazón es un valor, de este modo ratifica la creencia compartida y la utiliza a su favor. Este movimiento logra, al mismo tiempo definir la situación, cambiar la variedad estilística (de formal a informal ${ }^{\mathrm{II}}$ ) e instalar un marco de interpretación alternativo al reclamar el reconocimiento de la piedad en la acción. Esto genera un efecto interactivo en el oyente en términos de cambio actitudinal al evitar una nueva contraargumentación. El realineamiento del policía (Goffman, I98I) se refleja en el movimiento en la estructura de participación (Goffman, I98I) de animador de un principal ajeno (el COE - Comité de Emergencia de la Provincia de Santiago del Estero) a animador, autor y principal de su propia voz: si se quieren ir / ya son grandes señores/ yo no me opongo.

\footnotetext{
${ }^{\text {II }}$ Cf. el cambio estilístico como estrategia discursiva (Gumperz, I982).
} 


\subsection{Análisis de la entrevista periodística: la narrativa familiar}

La representación discursiva de la situación construye una narrativa familiar que ubica al padre como un valiente protector que salva a su hija del peligro. Los otros actores, el policía y la burocracia policial, aparecen en función opositiva. De la entrevista rescatamos dos momentos de evaluación (Labov, 20I3):

\section{Transcripción}

Periodista ¿qué pensás de todo esto?

Madre (no sé) que nos trataron (como) peores (mueve la cabeza) que mi hija no no le importó al policía verla a mi hija como estaba (se entrecorta por el llanto) que solamente le pedía, = solamente le pedía que queríamos pasar porque ya hacía bastante cALOR. =encima los bichos =y el policía no entendía le dije qué esperaba? orden? Decía que esperaba orden. de Santiago para que podamos pasar, siendo que a la mañana ni siquiera los(nos) han pedido nada. para pasar era algo muy feo lo que vivimos ayer con mi hija y como está ella ahora con las crisis, los dolores, (llora) cada vez que se despierta lo único que dice ese policía malo mamá mamá, que no me deja pasar para irme a mi casa, se asustó muy mucho con el tema de los bichos tenía miedo que se me infecione su pierna (suspire, llora) es algo que $=$

Periodista (...) que te impulsó?

Padre: (realmente) el problema que ella tiene y las moscas que estaban / estaba lleno de moscas y queee no no hacían nada para que nos dejen pasar porque nos han demorado mucho y no me quedaba otra que pasar sobre ellos pasar sobre ellos y retirar a mi hija retirarla de las moscas llevarla -aunque sea caminando / llevarla hasta que nos pudieran buscar / [se refiere al móvil de la municipalidad] 
y le -

(lloran los padres)

Tres días más tarde, en una entrevista con un medio nacional, TN, Carmen se presenta como vocera de la familia. Interpreta la experiencia a través de un posicionamiento epistémico y emocional y logra trasmitir con eficacia la evaluación externa de la narrativa (Labov \& Waletzky, I967), hemos vivido por eso le decimos /lo que es la realidad lo que hemos/vivido (era) un caos / llamábamos a uno a otro y nadie no- / atendía / hemos vivido una pesadilla.

Narrar un hecho de violencia, implica exponer una situación que, en general, es de difícil expresión para la víctima. El relato en los medios de Carmen deja en claro que lo que vivió en el retén no fue en caso de trato desigual o discriminatorio. Fue una pesadilla.

Por otra parte, cabe destacar la reconstrucción del entorno ambiental en las evaluaciones internas ${ }^{12}$ de ambos padres:

Madre: porque ya hacía bastante cALOR.

=encima los bichos =y el policía no entendía

Padre: y no me quedaba otra que pasar sobre ellos

pasar sobre ellos y retirar a mi hija

retirarla de las moscas

El entorno ambiental, el calor, las moscas, etc. se fragmenta en elementos de la naturaleza que se presentan en el relato como hechos objetivos, y toman función como motivadores de la acción, al modo de los relatos naturalistas. Para la familia Jiménez, salir de esa situación implicó un acto violento contraargumentativo ${ }^{13}$ : pasar sobre ellos / pasar sobre ellos y retirar a mi hija / retirarla de las moscas.

Por otra parte, los titulares y bajadas de las primeras notas (luego difundidas por medios regionales y nacionales) recontextualizan la narrativa familiar utilizando una macroestructura sociosemántica (van Dijk, I983) que resume

\footnotetext{
${ }^{12}$ Labov (2013) sostiene que la evaluación marca la parte central e informativa del relato, no obstante, podría aparecer cada vez que el hablante lo considere necesario.

${ }^{13}$ Interaccionalmente, se interpreta en términos de posicionamiento tridimensional (evaluación de objetos, posicionamiento del sujeto y alineamiento con los demás en una situación sociocultural específica, Du Bois, 2007).
} 
los elementos centrales que luego se repite en otros medios. A modo de ejemplo, presentamos la nota en la web de la radio La FM Termas Digital'14

\author{
(titular) UN PADRE INGRESÓ A LA PROVINCIA CON SU HIJA EN BRA- \\ ZOS PORQUE LA POLICÍA LES NEGABA EL INGRESO'5
}

(bajada) Los progenitores de una niña de I2 años, paciente oncológica, regresaban de Tucumán donde la habían asistido a la niña, y en el puesto caminero de Yutu Yacu le impidieron el ingres ${ }^{16}$.

(foto central del padre caminando en la ruta con Abigail en brazos)

(cuerpo de la nota) Un padre realizó una publicación en la red social Facebook donde contó la situación que le tocó vivir cuando retornó de la provincia de Tucumán junto a su pequeña hija de I2 años, la cual padece una grave enfermedad.

Diego Jiménez, papá de Abigail, una niña con una enfermedad oncológica, provenía en la siesta de ayer lunes desde la capital tucumana a donde había concurrido sin inconvenientes desde Las Termas, para hacer asistir a su hija por la grave enfermedad que la afecta. En el retorno, un policía habría impedido el ingreso supuestamente por no tener autorización, lo que motivó que Diego tomara en sus brazos a su hija y caminara con ella alrededor de 3 kilómetros ${ }^{17}$, según lo expresado por Carmen, la mamá de la niña, en diálogo en la mañana de este martes con FM TERMAS DIGITAL. Carmen accedió brevemente a contar la situación en medio de una crisis emocional, al momento que se encontraba por radicar denuncia en la oficina local de Derechos Humanos.

Como resultado de la operación resultiva (van Dijk, I983), se definen los actores (Diego Jiménez, papá de Abigail, una niña con una enfermedad oncológica y Carmen, la mamá de la niña), las circunstancias (provenía en la siesta de ayer lunes desde la capital tucumana), los motivos (para hacer asistir a su hija por la grave enfermedad que la afecta), a partir de la fuente informativa

\footnotetext{
${ }^{14}$ Disponible en: http://termasdigital.com.ar/un-padre-ingreso-a-la-provincia-con-su-hija-enbrazos-porque-la-policia-les-negaba-el-ingreso/ [Acceso 20/10/202I]

I5 La construcción causal con el agente explícito actúa claramente como expresión de posición negativa elegida como perspectiva de valor en la noticia (Bednarek \& Caple, 20I7).

${ }^{16}$ La noticia se construye desde la personalización y la proximidad local. De modo que el conjunto de referencias extradiscursivas definen un lector competente para reconocerlas (o no). Por otra parte la presentación de la familia -un padre, una niña de I2 años, la mamá en medio de una crisis emocional- funcionan como recursos de personalización del valor de la noticia (van Leeuwen, 2008; Bednarek \& Caple, 20I7).

${ }^{17}$ La cuantificación de la situación (caminar $3 \mathrm{~km}$ ) es uno de los recursos del realismo. Pero justamente fue puesta en cuestionamiento por las autoridades políticas, lo que motivó un cambio en el relato mediático (https://www.clarin.com/sociedad/gobierno-santiago-estero-desmintio-padre-entro-provincia-hija-enferma-brazos_o_FD8NMohOm.html).
} 
presentada en el primer párrafo como justificación evidencial (Un padre realizó una publicación en la red social Facebook). Describe también conductas posteriores al hecho inicial (radicar denuncia en la oficina local de Derechos Humanos).

La foto del padre con Abigail en brazos condensa la situación en marco de la narrativa familiar, es decir, la recontextualiza como imagen, la representación discursiva de los medios locales. Las recontextualizaciones de los otros medios van agregando nuevos rasgos semánticos. Aunque todos comparten una lectura de relevancia centrada en la acción del padre heroico, a veces, la prominencia de otros rasgos (la falta de sentido común del policía o el sufrimiento de la niña enferma) se relacionan en realidad con la práctica periodística en sí, como género (crónica, editorial o entrevista) y la política editorial del medio como empresa ${ }^{\text {I8 }}$.

\section{Interpretación de las estrategias}

La estrategia de presentación mediática fue homogénea. El video del retén fue presentado en crudo como recurso retórico. En el marco de la pandemia de la COVID-ig, que llevó al aislamiento social de millones de personas en el mundo, el llanto de Abigail, una niña de i2 años enferma terminal en la frontera de una de las provincias más pobres del país se escuchó una y otra vez y ocupó un lugar central en la construcción del acontecimiento noticioso en cuanto que expresión de una emoción negativa (Bednarek \& Caple, 20I7) que manifiesta el dolor, no lo describe (Pounds, 20I2). La perspectiva negativa en la valoración de la noticia aumenta la fuerza simbólica del padre llevando a su hija en brazos como un acto disruptivo y excepcional en una situación ya de por sí excepcional. Cabe destacar que los medios retoman la evaluación interna de la madre, que interpreta la acción policial como abuso de autoridad.

Abigail es una víctima sin voz no solo porque es niña y el discurso mediático se construye desde el mundo adulto antropocéntrico, sino porque la representación discursiva del dolor involucra mucho más que el detalle de los hechos. Nos interpela ante la experiencia directa e intransferible del sufri-

\footnotetext{
${ }^{18}$ En otras palabras, la recontextualización (en los medios) no solo hace más o menos explícita la práctica social recontextualizada, también la hace pasar por el filtro de las prácticas en las que se inserta (van Leuwen, 2008). Sin embargo, al mismo tiempo, vale destacar que en todas partes hay un puñado de procedimientos y formatos y pluralidad de discursos. En todos lados existe una homogeneidad genérica y una heterogeneidad discursiva (Machin \& van Leeuwen, 2003).
} 
miento y, aunque el dolor físico personal no puede compartirse, el discurso mediático cuenta con "una maleta repleta de recursos frente al sufrimiento del otro” (Allué, 2009: I68).

\section{Consideraciones finales}

El estudio del caso nos ayuda a entender cómo la violencia irrumpió en la vida familiar durante el aislamiento social, cuando las personas y las prácticas de salud se movieron a través de distintos contextos geográficos y sociales (SungYueh Perng, 2020). Explicada desde una perspectiva integral multidimensional, la violencia está instalada en la normalidad de nuestra vida cotidiana. Más aún, el abuso de poder se explica, en parte, en el posicionamiento de las personas en situación de sometimiento y dependencia (absoluta o relativa) cristalizadas en contextos político-sociales concretos y se manifiesta como amenaza (real o potencial) del uso de la fuerza y/o de los resortes institucionales y prerrogativas. De modo que cuando el padre de Abigail decide levantarla y llevarla en brazos no sabe si lo van a detener o no. La madre tampoco.

Con respecto a los medios, el análisis del discurso nos señala que los efectos discursivos operan por encima del nivel de lo individual y resultan relevantes y desafiantes en relación con la conceptualización de la violencia en sus distintas manifestaciones. El caso de Milagros Abigail Jiménez nos demuestra que es la falta de piedad humana lo que transforma cualitativamente el maltrato en una situación de violencia.

En el orden cultural, se consolida la figura de madre como intérprete del mundo interno de su hija y transforma el dolor individual en sufrimiento social; es mediadora entre la familia y el entorno social. Carmen va construyendo su posición actitudinal a lo largo de las entrevistas. De la interacción con los medios, va aprendiendo estrategias de intervención frente a la moral social.

\section{Bibliografía}

Allué, M. 2009. La gestión del dolor. En Grimberg, M. (ed.) Experiencias y narrativas de padecimientos cotidianos. Miradas antropológicas sobre la salud, la enfermedad y el dolor crónico. Buenos Aires: OPFyL, I67-I85.

Álvarez-Pereyre, M. 20II. Using film as linguistic specimen. Theoretical and practical issues. En Piazza, R. et al. (ed.) Telecinematic Discourse. Approaches to the language of films and television series. Amsterdam: John Benjamins. 
Amossy, R. 20I7. Apología de la Polémica. Buenos Aires: Prometeo.

Bednarek, M. \& Caple, H. 20I7. The Discourse of News Values: How News Organizations Create 'Newsworthiness'. Oxford: Oxford University Press, 77-Io6.

Brown P. \& Levinson, S. I987. Politeness. Some Universal in Language Usage. Cambridge: CUP.

Carrizo, A. E. 20I2. La argumentación interaccional: efectos del uso del discurso referido. Buenos Aires: OPFyL.

Carrizo, A. E. 20I9. Perspectiva interaccional de la argumentación en el análisis del discurso. En Londoño Zapata, O. I. \& Olave Arias, G. (coord.) Métodos de Análisis del Discurso. Perspectivas argentinas. Bogotá: Ediciones de la U, 67-93.

Moïse, C. \& Oprea, A. 20I5. Présentation. Politesse et violence verbale détournée. Semen 40. http://journals.openedition.org/semen/I0387 [Acceso 2I/IO/202I]

Condor, S. \& Antaki, C. 2000. Cognición social y discurso. En van Dijk, T. (comp.) El discurso como estructura Y proceso. Barcelona: Gedisa, 453-490.

Du Bois, J. W. 2007. The stance triangle. En Englebretson, R. (ed.) Stancetaking in Discourse. Subjectivity, Evaluation, Interaction. Amsterdam/Philadelphia: John Benjamins, I39-182.

Duranti, A. 2003. Language as Culture in U. S. Anthropology. Three Paradigms. Current Anthropology 44(3): 323-347.

Eisenberg, A. R. \& Garvey, C. A. I98I. Children's use of verbal strategies in resolving conflicts. Discourse processes 4(2): I49-I70.

Farmer, P. 2004. An Anthropology of Structural Violence. Current Anthropology 45(3): 305-325 http://www.jstor.org/stable/I0.I086/382250 [Acceso 25/05/2020]

Fracchiolla, B.; Romain, C.; Moïse, C. \& Auger, N. (ed.). 2013. Violences Verbales. Analyses, enjeux et perspectives. Rennes: Presses Universitaires de Rennes.

Garver, N. \& Friedenberg, E. I968. What Violence Is. The Nation 209: 8I7-822.

Goffman, E. I974. Frame Analysis. An Essay on the Organization of Experience. Boston: Northeastern University Press.

Goffman, E. I98I. Form of Talk. Philadelphia: Pennsylvania U.P.

Goffman, E. 200I. La presentación de la persona en la vida cotidiana. Buenos Aires: Amorrortu.

Grimshaw, A. (ed.) I990. Conflict talk: Sociolinguistic Investigations of Arguments in Conversations. Cambridge: Cambridge University Press.

Gumperz, J. I982. Discourse Strategies. Cambridge: CUP.

Halliday, M. A. K. I985. An Introduction to Functional Grammar, London: Edward Arnold.

Halliday, M. \& Matthiessen, C. (2004). An Introduction to Functional Grammar. London: Arnold.

Haverkate, H. I988. Toward a typology of politeness strategies in communicative interaction. Multilingüa 7-4: 385-409. Berlin: Mouton Gruyter.

Kerbrat-Orecchioni, C. I980. La polémique et ses définitions. En La parole polémique, Lyon: Presses Universitaires de Lyon, 3-40.

Labov, W. I972. Rules for ritual insults. En Sudnow, D. (ed.) Studies in Social Interaction. New York: Free Press, I20-169. 
Labov, W. 2013. The Language of Life and Death. The Transformation of Experience in Oral Narrative. Cambridge: University Press.

Labov, W. \& Waletzky, J. I967. Narrative analysis. En Helm, J. Essays on the verbal and Visual Arts. Seattle: University of Washington Press, I2-44.

Levinson, S. I988. Putting linguistics on a proper footing: explorations in Goffman's concepts of participation. En Drew, P. \& Wootton, A. (ed.) Erving Goffman: Exploring the Interaction Order. Berlín: Mouton de Gruyter, I6I-227.

Levinson, S. 1989. Pragmática. Barcelona: Teide.

Machin, D. \& van Leeuwen, T. 2003. Global Schemas and Local Discourses in Cosmopolitan. Journal of Sociolinguistics 7(4): 493-513.

Martin, J. R. \& White, P. R. R. 2005. The Language of Evaluation: Appraisal in English. London: Palgrave Macmillan.

Menéndez, S. M. 2009. Estrategias, registros y géneros discursivos: de la realización a la recurrencia. En Actas del IV Coloquio de ALEDAR: Universidad Nacional de Córdoba. http://www.fl.unc.edu.ar/aledar/index

Menéndez, S. M. 20I9. Entre la gramática y el género: el discurso. Un enfoque estratégico. En Londoño Zapata, O. I. \& Olave Arias, G. (coord.) Métodos de Análisis del Discurso. Perspectivas argentinas. Bogotá: Ediciones de la U, II5-I3I.

Moïse, C. 20I2. Argumentation, confrontation et violence verbale fulgurante. Argumentation et Analyse du Discours 8. http://aad.revues.org/ı260.

Pounds, G. 20I2. Multimodal expression of authorial affect in a British television news programme. Discourse, Context and Media I(2-3): 68-8I.

Pardo, M. L \& Carrizo, A. E. 20I8. El discurso sobre la violencia doméstica en historias de vida y sentencias jurídicas: el discurso en acción. Revista Latinoamericana de Estudios del Discurso. Raled I8(2): 6-22. http://raled.comunidadaled.org/ index.php /raled/article/view/304/265

Pardo, M. L. 2008. Una metodología para la investigación lingüística del discurso. En Pardo, M. L. (ed.) El discurso sobre la pobreza en América Latina. Santiago: Frasis, 55-78.

Rosier, L. 2007. Petit traité de l'insulte. Bruxelles: Edition Labor.

Rosier, L. 20I2. Introduction. En Argumentation et Analyse du Discours. http://aad. revues.org/132I [Acceso 27/03/2013]

Scheper-Hughes, N. \& Bourgois, P. 2004. Introduction: Making Sense of Violence. En Scheper-Hughes, N. \& Bourgois, P. (ed.) Violence in War and Peace: An Anthology. Londres: Blackwell, I-3I.

Sung-Yueh Perng. 2020. Ignorance, exclusion, and solidarity in human-virus co-existence during and after COVID-I9. Dialogues in Human Geography IO(2): I50I53.

Van Dijk, T. I983. La ciencia del texto. Barcelona/Buenos Aires: Paidós.

Van Dijk, T. 20I6. Estudios Críticos del Discurso: Un enfoque sociocognitivo. Discurso $y$ Sociedad Io(I): I67-I93.

Van Eemeren, F. H. \& Garssen, B. 2020. The pragma-dialectical view of comparison argumentation. En Dutilh Novaes, C.; Jansen, H.; van Laar, J. A.; Verheij, B. 
(ed.) Reason to Dissent: Proceedings of the 3rd European Conference on Argumentation, vol. II, 26I-274.

Van Eemeren, F. H.; Grootendorst, R. \& Henkemans, F. S. 2006. Argumentación. Análisis, evaluación, presentación. Buenos Aires: Biblos.

Van Leeuwen, T. 2008. Discourse and Practice. New Tools for Critical Discourse Analysis. New York: Oxford University Press.

Verschueren, J. 2002. Para entender la pragmática. Madrid: Gredos.

Vincent, D. \& Barbeau, G. B. 20I3. Insulte, disqualification, persuasion et tropes communicationnels: á qui l'insulte profite-t-ell? Argumentation et Analyse du Discours. http://aad.revues.org/1252 